\title{
Percutaneous balloon dilatation of aortic valve stenosis in neonates and infants
}

\author{
CHRISTOPHER WREN, * IAN SULLIVAN, $†$ CATHERINE BULL, $\dagger$ \\ JOHN DEANFIELD $\dagger$ \\ From the ${ }^{\star}$ Freeman Hospital, Newcastle upon Tyne and †The Hospital for Sick Children, London
}

SUMMARY Percutaneous balloon dilatation of severe aortic valve stenosis was attempted in thirteen patients (seven neonates and six infants). In two the valve could not be crossed and both died during subsequent operation. Two patients died during manipulation of the balloon catheter. No significant benefit was obtained in another patient who later died during operation. Balloon dilatation was successful in the remaining eight patients, reducing the aortic valve pressure gradient from a mean of $63 \mathrm{~mm} \mathrm{Hg}(95 \%$ confidence interval 38 to $88 \mathrm{~mm} \mathrm{Hg})$ to a mean of $23 \mathrm{~mm} \mathrm{Hg}$ ( $95 \%$ confidence interval 7 to $39 \mathrm{~mm} \mathrm{Hg}$ ). Two of these patients subsequently died from heart failure related to other cardiac lesions. The six survivors have done well. At follow up the maximum Doppler velocities in the ascending aorta ranged from 1.9 to $4.0 \mathrm{~m} / \mathrm{s}$ after $2-23$ months, but despite this evidence of an increasing valve gradient there has been lasting clinical improvement.

The development of balloon dilatation has altered the management of many stenotic lesions in paediatric cardiology and the technique is already widely used for relief of pulmonary valve stenosis and recoarctation of the aorta. In most other situations balloon dilatation remains experimental and will only supersede operative management if it can equal or improve upon the results of surgery.

The treatment of critical aortic valve stenosis in infancy is difficult and the surgical mortality is high. ${ }^{2}$ Palliation by surgical valvotomy may produce long lasting benefit but repeat operation is often necessary and is associated with a higher mortality. ${ }^{3}$ If the efficacy, morbidity, and mortality of balloon dilatation can match the results of surgical valvotomy in these patients, it may provide an attractive alternative approach to initial management. Isolated reports of successful balloon dilatation in infancy, however, may give a falsely optimistic impression of the procedure. ${ }^{4-6}$ This paper reports our experience in 13 consecutive patients who were younger than 12 months and had aortic valve stenosis.

Requests for reprints to Dr Christopher Wren, Department of Paediatric Cardiology, Freeman Hospital, Newcastle upon Tyne NE7 7DN.

Accepted for publication 3 August 1987

\section{Patients}

Between June 1985 and April 1987 seven nenonates and six infants underwent cardiac catheterisation with a view to performing balloon dilatation of severe aortic valve stenosis (table). Their ages ranged from one day to 11 months (median four weeks) and their weights from 1.5 to $8.9 \mathrm{~kg}$. Ten patients had signs of heart failure and three had already undergone surgical valvotomy. One patient (case 3 ) had coexisting severe mitral valve stenosis. Patient 10 was born 14 weeks prematurely and developed bronchopulmonary dysplasia despite ligation of the ductus arteriosus. Patient 6 was born at 26 weeks' gestation and in addition to critical aortic stenosis she had severe left ventricular dysfunction and mitral valve stenosis, and subsequently underwent ligation of a ductus arteriosus.

The electrocardiogram demonstrated left ventricular hypertrophy in all patients, with repolarisation abnormalities in six. Echocardiography showed hypertrophy, dilatation, and impaired contraction of the left ventricle in five patients and small ventricles with concentric hypertrophy in the remainder; two of these having very small left ventricular cavities similar to those seen in the hypoplastic left heart syndrome (table). 
Table Details of patients with aortic stenosis treated by balloon dilatation

\begin{tabular}{|c|c|c|c|c|c|c|c|c|c|c|}
\hline \multirow[b]{2}{*}{ Patient } & \multirow[b]{2}{*}{ Age } & \multirow{2}{*}{$\begin{array}{l}\text { Weight } \\
(\mathrm{kg})\end{array}$} & \multirow{2}{*}{$\begin{array}{l}L V \\
\text { function }\end{array}$} & \multirow{2}{*}{$\begin{array}{l}\text { Balloon } \\
\text { diameter } \\
(\mathbf{m m})\end{array}$} & \multicolumn{2}{|c|}{$\begin{array}{l}\text { AOV gradient } \\
(\mathrm{mm} \stackrel{\mathrm{Hg}}{ })\end{array}$} & \multirow{2}{*}{$\begin{array}{l}A R \\
\text { grade }\end{array}$} & \multirow{2}{*}{$\begin{array}{l}\text { Follow up } \\
\text { (months) }\end{array}$} & \multirow{2}{*}{$\begin{array}{l}\text { Doppler } \\
(\mathrm{m} / \mathrm{s})\end{array}$} & \multirow[b]{2}{*}{ Comments } \\
\hline & & & & & Before & After & & & & \\
\hline 1 & 1 day & $2 \cdot 2$ & $\mathbf{H}$ & - & - & - & - & - & - & Valve not crossed, died \\
\hline 2 & 6 day & 3.0 & $\mathbf{S}$ & - & 93 & - & - & - & - & $\begin{array}{l}\text { Died during balloon } \\
\text { catheter manipulation }\end{array}$ \\
\hline 3 & 13 day & $2 \cdot 8^{\star}$ & D & 6 & 64 & 44 & 0 & - & - & $\begin{array}{l}\text { Died in heart failure from } \\
\text { mitral stenosis }\end{array}$ \\
\hline 4 & 14 day & $3 \cdot 5$ & $\mathbf{H}$ & 6 & 7 & 19 & 0 & 23 & 1.9 & Ventricular function has \\
\hline $\begin{array}{l}5 \\
6\end{array}$ & $\begin{array}{l}21 \text { day } \\
22 \text { day }\end{array}$ & $\begin{array}{l}3.8 \\
1.5\end{array}$ & $\begin{array}{l}\mathrm{D} \\
\mathrm{D}\end{array}$ & $\begin{array}{l}7 \\
5\end{array}$ & $\begin{array}{l}86 \\
40\end{array}$ & $\begin{array}{r}5 \\
10\end{array}$ & $\begin{array}{l}0 \\
1-2\end{array}$ & 13 & $\frac{3 \cdot 1}{-}$ & $\begin{array}{l}\text { Remains well } \\
\text { Died from persisting hear } \\
\text { failure }\end{array}$ \\
\hline 7 & 28 day & $3 \cdot 0^{\star}$ & $\mathbf{S}$ & 6 & 50 & - & - & 一 & - & $\begin{array}{l}\text { Died after aortic root } \\
\text { replacement }\end{array}$ \\
\hline $\begin{array}{l}8 \\
9\end{array}$ & $\begin{array}{l}30 \text { day } \\
2 \text { mth }\end{array}$ & $\begin{array}{l}3 \cdot 5 \\
4 \cdot 2\end{array}$ & $\begin{array}{l}\text { S } \\
\text { D }\end{array}$ & $\begin{array}{l}6 \\
6\end{array}$ & $\begin{array}{l}50 \\
60\end{array}$ & 30 & 0 & $\underline{2}$ & $\frac{4 \cdot 0}{-}$ & $\begin{array}{l}\text { Remains well } \\
\text { Died during balloon } \\
\text { inflation }\end{array}$ \\
\hline $\begin{array}{l}10 \\
11 \\
12\end{array}$ & $\begin{array}{l}5 \mathrm{mth} \\
7 \mathrm{mth} \\
8 \mathrm{mth}\end{array}$ & $\begin{array}{l}5 \cdot 6 \\
6 \cdot 9 \\
4 \cdot 2\end{array}$ & $\begin{array}{l}\text { S } \\
\text { D } \\
\text { S }\end{array}$ & $\begin{array}{l}8 \\
8 \\
-\end{array}$ & $\begin{array}{r}103 \\
80 \\
-\end{array}$ & $\begin{array}{r}6 \\
60 \\
-\end{array}$ & 1 & $\begin{array}{r}8 \\
14 \\
-\end{array}$ & $\begin{array}{l}2 \cdot 8 \\
3 \cdot 5 \\
-\end{array}$ & $\begin{array}{l}\text { Remains well } \\
\text { Remains well } \\
\text { Valve not crossed, } \\
\text { died after operation }\end{array}$ \\
\hline 13 & $11 \mathrm{mth}$ & $8 \cdot 9 *$ & $\mathbf{S}$ & 9 & 76 & 9 & 1 & 13 & $2 \cdot 5$ & Remains well \\
\hline
\end{tabular}

$A O V$, aortic valve; $A R$, aortic regurgitation; $D$, dilated hypertrophic left ventricle; $H$, hypoplastic left ventricle; $L V$, left ventricle; $S$, small hypertrophied left ventricle; `previous surgical valvotomy.

\section{Methods}

Cardiac catheterisation was performed under general anaesthetic in ten patients and with sedation and local anaesthesia in three. Catheters were introduced by percutaneous femoral artery puncture in five patients and by elective femoral artery cut down in the remainder. Heparin (100 units $/ \mathrm{kg}$ body weight) was given. The balloon chosen was at least 1-2 mm smaller than the valve diameter measured from a cineaortogram. The aortic valve was crossed with an end-hole catheter, usually with the help of a guide wire. The balloon catheter was advanced over an exchange guide wire with no arterial sheath. The balloon was positioned across the valve and inflated 1-4 times to produce and then to abolish waisting (fig 1). The catheter was then withdrawn and the pressure measurements (fig 2) and aortogram were repeated. In these small ill patients the procedure was kept as short as possible. Right heart catheterisation was not performed and no measurement of cardiac output or estimation of aortic valve area was possible.

\section{Results}

Balloon dilatation was accomplished safely in nine patients (table). In two further patients the aortic valve could not be crossed; both were referrred for open valvotomy and both died after operation. One patient died during manipulation of the balloon catheter around the aortic arch when only the guide wire was across the aortic valve. Permission for a necropsy was refused and the cause of death was not established. Another patient became asystolic after the first balloon inflation and could not be resuscitated. At necropsy there was no evidence of aortic rupture or other structural damage. The valve was dysplastic with three thickened leaflets and distinct commissures. Comparison with the echocardiogram and aortogram obtained before balloon dilatation suggested that the valve had split along the commisures. In one patient whose femoral artery was damaged during exchange of balloon catheters no post-dilatation pressures could be recorded. There was no clinical improvement and the patient died after attempted replacement of the aortic root.

After balloon dilatation pressures were recorded in eight patients and in seven of these the valve gradients before dilatation were between 40 and $103 \mathrm{~mm} \mathrm{Hg}$ (mean $63 \mathrm{~mm} \mathrm{Hg}, 95 \%$ confidence interval 38 to $88 \mathrm{~mm} \mathrm{Hg}$ ) (fig 3). In patient 4 the aortic valve gradient measured only $7 \mathrm{~mm} \mathrm{Hg}$ but there was clinical evidence of a very low cardiac output and the clinical, echocardiographic, and angiographic diagnosis was severe aortic valve stenosis with a small, poorly functioning left ventricle.

The diameters of the inflated balloon catheters used were between 5 and $9 \mathrm{~mm}$. In seven of the nine patients smaller balloon catheters were used initially but did not produce satisfactory results. Attempts to insert an $8 \mathrm{~mm}$ balloon in patient 7 caused laceration of the femoral artery and the procedure was abandoned. In patient 11 a $10 \mathrm{~mm}$ balloon catheter could 


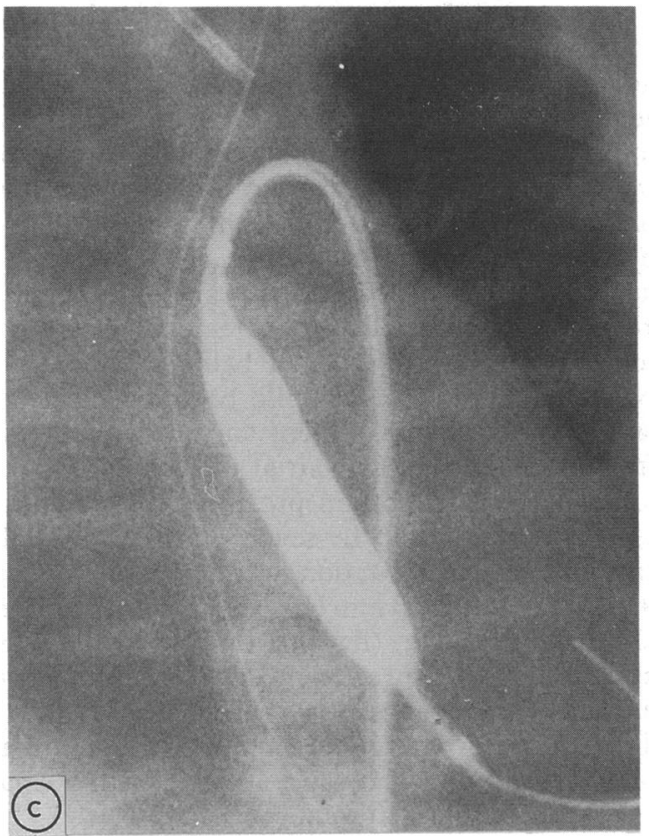

not be introduced into the femoral artery. In both these patients the result achieved with smaller balloons was disappointing.

After balloon dilatation the peak to peak systolic pressure gradient was reduced in the seven patients

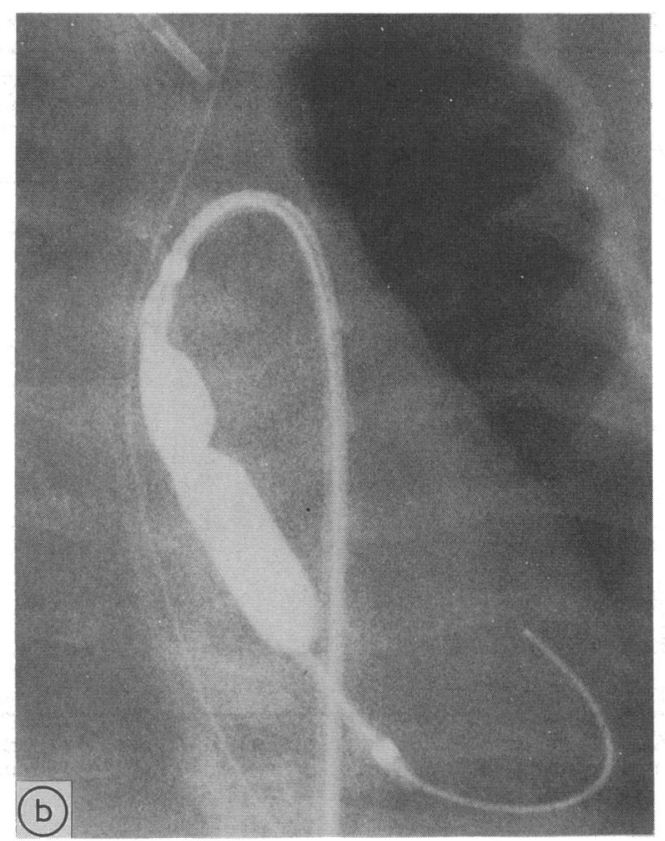

Fig 1 Frames from an anteroposterior cineangiogram from patient 5 showing the uninflated balloon in position across the aortic valve ( $a$ ) and partial (b) and complete (c) inflation of the balloon. Note that the waisting of the balloon was abolished at full inflation.

who had considerable gradients initially (fig 3 ) and had increased in patient 4 . The residual gradients were between 5 and $60 \mathrm{~mm} \mathrm{Hg}$ (mean $23 \mathrm{~mm} \mathrm{Hg}$, $95 \%$ confidence interval 7 to $39 \mathrm{~mm} \mathrm{Hg}$ ). Repeat aortic angiography did not show appreciable aortic 


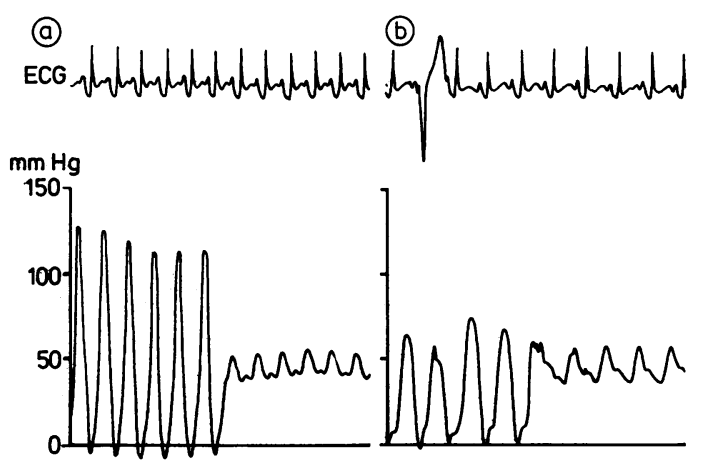

Fig 2 Pressure recordings during catheter withdrawal from the left ventricle to the ascending aorta in patient 5 (a) before and (b) after balloon dilatation.

regurgitation (table).

Seven of the 13 patients in this series died-two during the procedure (as described above), three during subsequent operation, and two in the month after balloon dilatation. Both of the last patients still required artificial ventilation for intractable pulmonary oedema. Patient 3 had severe mitral valve stenosis and patient 6 had mitral valve stenosis and severely impaired left ventricular function that failed to improve despite effective balloon dilatation and ligation of a ductus arteriosus.

Two of the six survivors had occlusion of the femoral artery after balloon dilatation (one had had percutaneous puncture and the other a cut down on the femoral artery) and both underwent successful femoral artery embolectomy. There were no arterial complications in the other four patients, two of whom had percutaneous puncture while the other two underwent femoral artery cut down.

At follow up examination after 2-23 months all six patients were well. None had signs of heart failure or required diuretic treatment. Non-invasive assessment included Doppler echocardiography. Maximum velocities in the ascending aorta at the most recent examination ranged from 1.9 to $4.0 \mathrm{~m} / \mathrm{s}$ (table) and correlated well with the measured gradient in the two patients who underwent repeat cardiac catheterisation.

\section{Discussion}

At first sight the results achieved in this series appear disappointing, with seven deaths and six survivors. None the less, three patients were only included because they had significant residual aortic stenosis causing persisting heart failure after surgical valvotomy and three others because they were unsuitable for operation-one weighed only $1.5 \mathrm{~kg}$ (patient 6) and in two others the left ventricle was thought to be too small for long term survival (patients 1 and 4). Three of the seven deaths occurred during subsequent operation and were not related to the balloon procedure. Two further deaths resulted from persisting heart failure related to other cardiac lesions.

None of the five patients weighing $\leqslant 3 \mathrm{~kg}$ survived long term. In comparison, only two of eight patients larger than $3 \mathrm{~kg}$ died, one of them during a subsequent surgical operation. Thus small size is an important risk factor, probably partly for technical reasons, but mainly because those with the most severe valve stenosis, the most important associated lesions, and the worst clinical condition will tend to present earliest.

Balloon dilatation of the aortic valve in these small patients is technically difficult. Introduction of the balloon catheter into the femoral artery risks damage to the vessel. ${ }^{7}$ Our results show that both cut down and percutaneous puncture may be complicated by arterial occlusion and neither approach has been shown to be better. In no case was arterial access not achieved, but in two patients the aortic valve could not be crossed and a surgical valvotomy was then the only option.

Death during balloon dilatation of the aortic valve in infancy has been reported before and was found at necropsy to be caused by laceration of the aortic wall. ${ }^{8}$ This was attributed by the authors to the balloon bursting in the ascending aorta but may have resulted from manipulation of the balloon catheter in the aortic arch. The balloon did not burst during

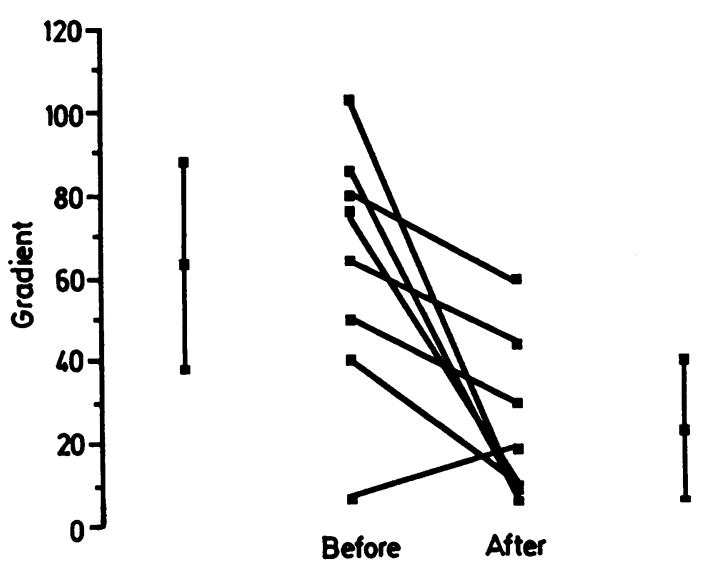

Fig 3 Peak to peak pressure gradients between left ventricle and ascending aorta before and after balloon valvotomy. Vertical bars indicate $95 \%$ interval. The mean gradient was reduced from $63 \mathrm{~mm} \mathrm{Hg}$ (95\% confidence interval 38 to $88 \mathrm{~mm} \mathrm{Hg}$ ) to $23 \mathrm{~mm} \mathrm{Hg}$ (95\% confidence interval 7 to $39 \mathrm{~mm} \mathrm{Hg}$ ). 
treatment of either of our patients who died during the procedure, and the aorta was intact in the case examined at necropsy.

Rupprath and Neuhaus reported success using coronary balloon catheters of up to $4.2 \mathrm{~mm} .{ }^{59}$ In five of our nine patients initial results with balloons measuring $3.5-10 \mathrm{~mm}$ in diameter were inadequate and we would not recommend use of coronary balloon catheters except in very small babies. On the other hand, it is important that balloons with diameters larger than the aortic valve ring are not used. Intraoperative dilatation with oversize balloons in neonates produces a high incidence of fatal aortic valve damage. ${ }^{10}$

Follow up assessment by Doppler echocardiography has suggested that the aortic valve gradients are increasing. This may reflect an increase in the severity of the valve stenosis, or the difference between catheter and Doppler measurement of valve stenosis, or (perhaps more likely) an improvement in cardiac output after reduction of the obstruction. All follow up examinations were outpatient procedures performed without sedation and instantaneous peak velocity was measured.

An improvement in the results of percutaneous balloon dilatation of aortic valve stenosis in this difficult group of patients can be expected with increasing practical experience, developments in balloon catheter design, and, perhaps, better patient selection. The procedure may provide an alternative to initial surgical management in some patients. Relief of aortic valve stenosis in patients weighing $<3 \mathrm{~kg}$, however, is likely to continue to have a significant mortality, whether performed surgically or by catheter.

We thank Dr H H Bain, Dr S Hunter, Dr P G Rees, and Dr J F N Taylor for allowing us to report details of patients under their care.
References

1 Sink JD, Smallhorn JF, Macartney FJ, Taylor JFN, 응 Stark J, de Leval MR. Management of critical aortic $\overline{\bar{D}}$ stenosis in infancy. $J$ Thorac Cardiovasc Surg 1984;87:82-6.

2 Duncan $K$, Sullivan I, Robinson $P$, Horvath $P$, ळ de Leval $M$, Stark J. Transventricular aortic $\vec{\circ}$ valvotomy for critical aortic stenosis in infants. J Thorac Cardiovasc Surg 1987;93:546-50.

3 Binet JP. Critical aortic stenosis: surgical results in infancy. In: Doyle EF, Engle MA, Gersony WM, Rashkind WJ, Talner NS, eds. Pediatric cardiology. New York: Springer Verlag, 1986:653-6.

4 Sanchez GR, Mehta AV, Ewing LL, Brickley SE, Anderson T, Black IFS. Successful percutaneous balloon valvuloplasty of the aortic valve in an infant. Pediatr Cardiol 1985;6:103-6.

5 Rupprath G, Neuhaus KL. Percutaneous balloon aortic valvuloplasty in infancy and childhood. In: $\mathbb{D}$ Doyle EF, Engle MA, Gersony WM, Rashkind WJ, Talner NS, eds. Pediatric cardiology. New York: Springer Verlag, 1986:331-3.

6 Lababidi $Z$, Weinhaus L. Successful balloon valvuloplasty for neonatal critical aortic stenosis. Am Heart $J$ 1986;112:913-6.

7 Keane JF, Helgason H, Fellows KE, Lock JE. Results and complications of balloon valvotomy for congenital aortic stenosis [Abstract]. Circulation 1986;74 (suppl II):II-2.

8 Waller BF, Girod DA, Dillon JC. Transverse aortic wall tears in infants after balloon angioplasty for $\triangle$ aortic valve stenosis. J Am Coll Cardiol 1984; 4:1235-41.

9 Rupprath G, Neuhaus KL. Percutaneous balloon valvuloplasty for aortic valve stenosis in infancy. Am J Cardiol 1985;55:1655-6.

10 Phillips RR, Gerlis LM, Wilson N, Walker DR. Aortic valve damage caused by operative balloon dilatation of critical aortic valve stenosis. Br Heart J 1987; 57:168-70. 